ELSEVIER $\quad$ Microbes and Infection 10 (2008) 628-634

Original article

\title{
Physical stress primes the immune response of Galleria mellonella larvae to infection by Candida albicans
}

\author{
Peter Mowlds, Aoife Barron, Kevin Kavanagh* \\ Department of Biology, Medical Mycology Unit, NICB, National University of Ireland Maynooth, Co. Kildare, Ireland \\ Received 30 November 2007; accepted 13 February 2008 \\ Available online 23 February 2008
}

\begin{abstract}
Larvae of the greater wax moth (Galleria mellonella) that had been subjected to physical stress by shaking in cupped hands for 2 min showed reduced susceptibility to infection by Candida albicans when infected $24 \mathrm{~h}$ after the stress event. Physically stressed larvae demonstrated an increase in haemocyte density and elevated mRNA levels of galiomicin and an inducible metalloproteinase inhibitor (IMPI) but not transferrin or gallerimycin. In contrast, previous work has demonstrated that microbial priming of larvae resulted in the induction of all four genes. Examination of the expression of proteins in the insect haemolymph using 2D electrophoresis and MALDI TOF analysis revealed an increase in the intensity of a number of peptides showing some similarities with proteins associated with the insect immune response to infection. This study demonstrates that non-lethal physical stress primes the immune response of G. mellonella and this is mediated by elevated haemocyte numbers, increased mRNA levels of genes coding for two antimicrobial peptides and the appearance of novel peptides in the haemolymph. This work demonstrates that physical priming increases the insect immune response but the mechanism of this priming is different to that induced by low level exposure to microbial pathogens.
\end{abstract}

(C) 2008 Elsevier Masson SAS. All rights reserved.

Keywords: Galleria mellonella; Antimicrobial proteins; Candida; Host defence; 2D gel electrophoresis; MALDI TOF analysis; Gene expression

\section{Introduction}

The cellular immune response of insects is mediated by haemocytes while the humoral response is mediated by the production of a range of antimicrobial peptides (AMPs) and melanisation [1]. The insect immune response bears a number of similarities to the innate immune response of mammals and as a result various insects have been utilised for assessing the pathogenicity of bacterial [2] and fungal isolates [3] and for assessing the efficacy of a variety of antimicrobial drugs. Positive correlations between the virulence of microbial pathogens in insects and mammals [4,5] have been established and the use of insects for screening microbial mutants or antimicrobial drugs is now recognized as a valuable approach to reduce the need to use mammals for this type of testing [6].

\footnotetext{
* Corresponding author. Tel.: +3531 708 3859; fax: +3531708 3845 .

E-mail address: kevin.kavanagh@nuim.ie (K. Kavanagh).
}

Although insects lack an immune response equivalent to the adaptive immune response of vertebrates they are still capable of dealing with the entry of microbial pathogens and parasites in a rapid and effective manner [1]. The cellular immune response consists of haemocytes which function to phagocytose and encapsulate invading cells, or form nodules around larger structures (e.g. eggs of parasitic wasps). The humoral immune response is mediated by the production of a range of antimicrobial peptides, the formation of melanin or the coagulation of haemolymph to seal ruptures in the cuticle or retard the passage of pathogens. AMPs are released from a range of organs and cells $[7,8]$ into the haemolymph of the insect where they diffuse to the site of infection and attack components of the bacterial or fungal cell wall [9].

Although lacking an adaptive immune response it is well established that exposure of insects to low levels of a pathogen [10] or pathogen associated material (e.g. glucan, LPS) leads to priming of the immune response and enhanced protection against a subsequent infection with a potentially lethal dose of 
pathogen $[11,12]$. We have previously established that exposure of larvae of Galleria mellonella to low doses of yeast or fungal cell wall material induces genes coding for antimicrobial peptides and the appearance of novel immune related peptides in the haemolymph [12]. While immunological priming has clear benefits for an insect and may allow it to withstand a subsequent lethal infection it does carry a biological cost and, in the absence of compensatory feeding, can be fatal [13].

In this work the immune response of physically stressed G. mellonella larvae to infection with Candida albicans was examined to determine whether physical stress could prime the immune response and to ascertain whether the nature of the priming was different to that previously observed in microbially challenged larvae [12].

\section{Materials and methods}

\subsection{Chemicals and reagents}

All chemicals and reagents were of the highest purity and were purchased from Sigma-Aldrich Chemical Company Ltd (Dorset, UK) unless stated otherwise.

\subsection{Yeast strains and culture conditions}

C. albicans MEN (kindly donated by Dr. D. Kerridge, Cambridge, UK) was employed in this work and yeast cultures were grown as described previously [12].

\subsection{Insect larvae}

Sixth instar larvae of G. mellonella (Lepidoptera: Pyralidae, the greater wax moth) (Mealworm Company, Sheffield, England) were stored in wood shavings in the dark at $15^{\circ} \mathrm{C}$ [3]. Larvae ( 0.2 and $0.4 \mathrm{~g}$ ) were randomly chosen and all experiments were performed on three independent occasions. Larvae were inoculated with $5 \times 10^{5}$ yeast cells per $20 \mu$ through the last pro-leg into the haemolymph as described previously [12].

\subsection{Physical stress treatments of insect larvae}

Larvae were shaken in cupped hands through a distance of $25 \mathrm{~cm}$ in a vertical motion back and forth at a frequency of 80 times per minute for a period of $2 \mathrm{~min}$ before being transferred to $30{ }^{\circ} \mathrm{C}$ for $24 \mathrm{~h}$ prior to inoculation with $C$. albicans. Postinoculation, larvae infected with $C$. albicans were incubated at $30^{\circ} \mathrm{C}$. Ten larvae were used per treatment and all the experiments were performed on three independent occasions.

\subsection{Determination of haemocyte density}

Haemocyte density was assessed by bleeding three larvae into a pre-chilled microcentrifuge tube containing a few granules of phenylthiourea to prevent melanisation. Dilutions were made by mixing the haemolymph with $0.37 \%(\mathrm{v} / \mathrm{v})$ mercaptoethanol in sterile PBS and the haemocyte density was assessed with the aid of a Neubauer haemocytometer.
Experiments were performed on three independent occasions and the means $\pm \mathrm{SE}$ were determined.

\subsection{Induction of immune relevant proteins of G. mellonella by $R T-P C R$}

Larval RNA was extracted using TRI-reagent at 0, 4, 18, 24 and $48 \mathrm{~h}$ post the stress event. RNA ( $2 \mathrm{mg}$ ) was treated with DNase I prior to cDNA synthesis using the SuperScript Kit (Invitrogen) with oligo(dT) primers. RNA was extracted from each treatment on three independent occasions and quantification was performed using gel analysis and Gene tools software (Syngene).

PCR amplification of target genes was performed with primers and following the same conditions as listed in Ref. [12] and cycled 35 times. All samples were normalised to the corresponding $\beta$ actin value. The highest level of expression in a series was set to $100 \%$ and other values of that series are given as the percentage relative expression [10].

\subsection{Two-dimensional gel electrophoretic separation of haemolymph proteins}

Haemolymph was collected from control and physically stressed larvae into a pre-chilled microcentrifuge tube. A cocktail of protease inhibitors $(10 \mu \mathrm{g} / \mathrm{ml}$ leupeptin, pepstatin A, aprotinin and tosyl-lysylchloromethane (TLCK)) was added to the haemolymph, which was concentrated at $800 \times \mathrm{g}$ for $5 \mathrm{~min}$ to remove haemocytes and cell debris. Haemolymph was solubilised in IEF buffer for 30-60 min at room temperature with occasional vortexing.

Iso-electric focusing (IEF) was performed with $0.3 \mathrm{mg}$ of haemolymph protein loaded on $13 \mathrm{~cm}$ IPG strips (Amersham Biosciences UK Ltd) as described previously [12]. The IPG strips were applied to a $10 \%$ SDS-PAGE slab gel in a Biorad protean gel rig. Running buffer $(5 \mathrm{X})$ was placed in the internal chamber of the gel rig and gels were electrophoresed overnight at $50 \mathrm{~V}$ at room temperature. Separated proteins were visualised by Coomassie staining.

\subsection{Image acquisition and analysis}

Each 2D gel was scanned on a Hewlett Packard Scanjet $5100 \mathrm{c}$ Scanner and the images analysed with ImageMaster 2D Platinum v7 software (Amersham Biosciences UK Ltd). The protein spots of interest on each gel were detected, normalised, edited and manually matched to a reference gel. Proteins separated by $2 \mathrm{D}$ electrophoresis were quantified in terms of their relative volume (\% vol). Proteins that were up- or downregulated and proteins that appeared or disappeared under one condition or another were selected for analysis with MS. The mean increase/decrease in spot intensity was determined based on three independent gels per treatment.

\subsection{Protein identification by MALDI TOF analysis}

Mass spectrometry of trypsin digested proteins was performed using an Ettan ${ }^{\mathrm{TM}}$ MALDI-TOF spectrometer 
(Amersham Biosciences, GmbH, Freiburg, Germany) as described previously [12]. The resulting mass list from the tryptic-digested protein was analysed using ProFound peptide mapping version 4.10 .5 developed by Rockefeller University (http://www.unb.br/cbsp/paginiciais/profound.htm). The taxonomy used to identify tryptic fingerprint was Drosophila and other Metazoa with a tolerance mass error of 1.0 Da. Verification of sequences was performed using a BLAST search on the NCBI website (http://www.ncbi.nlm.nih.gov) to identify conserved domains of protein families. A Z score greater than 1.65 represents a $95 \%$ confidence level.

\subsection{Statistical analysis}

All assays were performed on three independent occasions. Results are expressed as the mean \pm SE. Survival curves were analysed with the log rank (Mantel-Cox) method utilising GraphPad Prism version 5 software. The variations in mRNA levels were compared by $t$ test (two tailed, variance of 3 method) using Sigma Stat Statistical analysis Package Version 1.00 (SPSS Inc, Chicago, IL, USA). Differences were considered significant at $p \leq 0.05$.

\section{Results}

\subsection{Effect of physical stress on the susceptibility of Galleria larvae to fungal infection}

Previous work has established that exposure of larvae of G. mellonella to fungal cells or fungal cell wall material induces an immune response that reduces the susceptibility of larvae to subsequent infection by $C$. albicans [12]. In the work presented here larvae were subjected to mild physical stress as described and incubated for $24 \mathrm{~h}$ at $30^{\circ} \mathrm{C}$ before being inoculated with C. albicans at a density of $5 \times 10^{5} /$ larva. Shaking of larvae had no adverse effect on survival over a $72 \mathrm{~h}$ period. The results (Fig. 1) indicate that the survival of control larvae (i.e. unstressed and infected) was $23.3 \pm 7.7 \%, 20 \pm 7.3 \%$ and $10 \pm 5.4 \%$ at 24,48 and $72 \mathrm{~h}$, respectively. In contrast, physically stressed larvae showed survival rates of $80 \pm 7.3 \%$, $53.3 \pm 9.1 \%$ and $50 \pm 9.1 \%$ at the same time points. Analysis of the survival curves indicated a statistically greater survival in stressed larvae, compared to unstressed larvae, at $p<0.0001$ using the log rank (Mantel Cox) test. These results indicate that physically stressing larvae $24 \mathrm{~h}$ prior to inoculation with $C$. albicans reduces the sensitivity of larvae to microbial infection.

\subsection{Analysis of the effect of physical stress on haemocyte density in $\mathrm{G}$. mellonella larvae}

The insect immune response consists of interacting cellular and humoral components [1]. Haemocytes represent the main element of the cellular response and the numbers of circulating haemocytes can vary depending upon the stage of the insect's lifecycle and in response to infection. The number of haemocytes in larvae that had been physically stressed was assessed

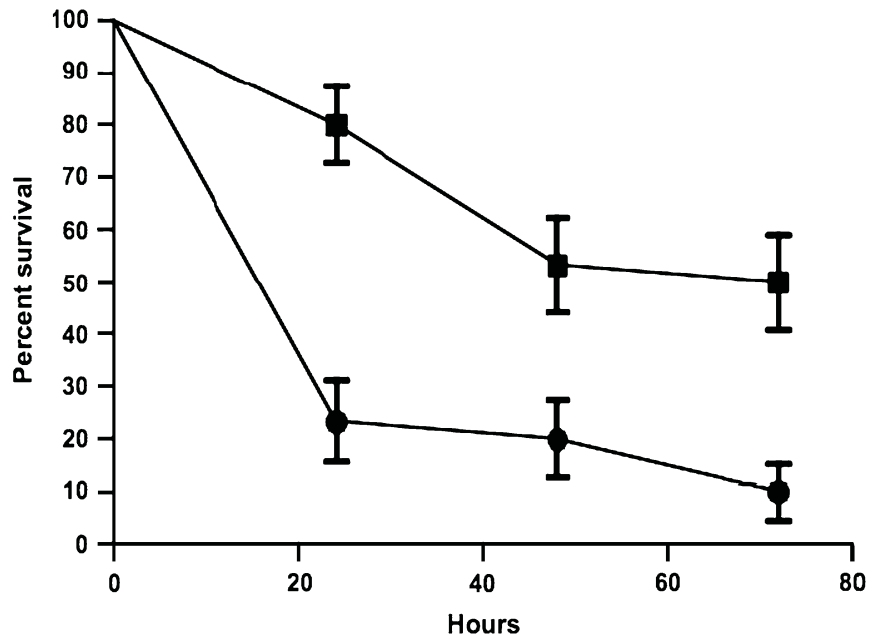

Fig. 1. Survival (\%) of physically stressed G. mellonella larvae inoculated with C. albicans. Larvae were physically stressed by shaking for $2 \mathrm{~min} 24 \mathrm{~h}$ prior to inoculation with $5 \times 10^{5}$ cells of $C$. albicans. All values represent the mean + $\mathrm{SE}$ from three independent experiments. (Control (unstressed and infected) larvae: circles; stressed and infected larvae: squares.)

24 and $48 \mathrm{~h}$ after the stress event. The number of haemocytes in physically stressed larvae was twice as high at $24 \mathrm{~h}$ $\left(6.6 \pm 0.37 \times 10^{5}\right.$ haemocytes/larva) compared to the control $\left(3.2 \pm 0.25 \times 10^{5}\right.$ haemocytes/larva $)(p=0.002)$. At $48 \mathrm{~h}$ the haemocyte density in physically stressed larvae was $6.76 \pm 0.39 \times 10^{5}$ haemocytes/larva while that of the control was $2.9 \pm 0.45 \times 10^{5}$ haemocytes/larva $(p=0.003)$. These results indicate that physical stress induces an increase in the number of circulating haemocytes which may play a role in the increased survivability demonstrated following yeast or bacterial infection.

\subsection{Gene expression of proteins involved in an immune response}

During an immune reaction to microbes, the up-regulation of proteins of the insect immune system has been observed [10]. We have previously demonstrated that pre-exposure of G. mellonella larvae to a sub-lethal dose of $C$. albicans induces a number of genes coding for antimicrobial peptides [12].

The mRNA levels of genes coding for proteins and peptides involved in this protective immune response within larvae following mild physical stress were assessed. Larvae were physically stressed as described, RNA was extracted from whole larvae over $48 \mathrm{~h}$ and cDNA was generated. The genes that were examined coded for galiomicin, a defensin identified in G. mellonella [14], a cysteine rich antifungal peptide gallerimycin [15], transferrin, an iron binding protein and an inducible metalloproteinase inhibitor (IMPI) from G. mellonella [16] (Fig. 2).

In the case of galiomicin, physical stress induced a relative expression of $76.2 \pm 3.2 \%$ after $1 \mathrm{~h}$ rising to a level of $92.1 \pm 7.3 \%$ at $24 \mathrm{~h}$ (Fig. 3). In contrast expression of galiomicin in control larvae remained below $26.1 \pm 0.3 \%$ throughout the duration of the experiment. The mRNA levels of galiomicin at $48 \mathrm{~h}$ were statistically greater in physically stressed 

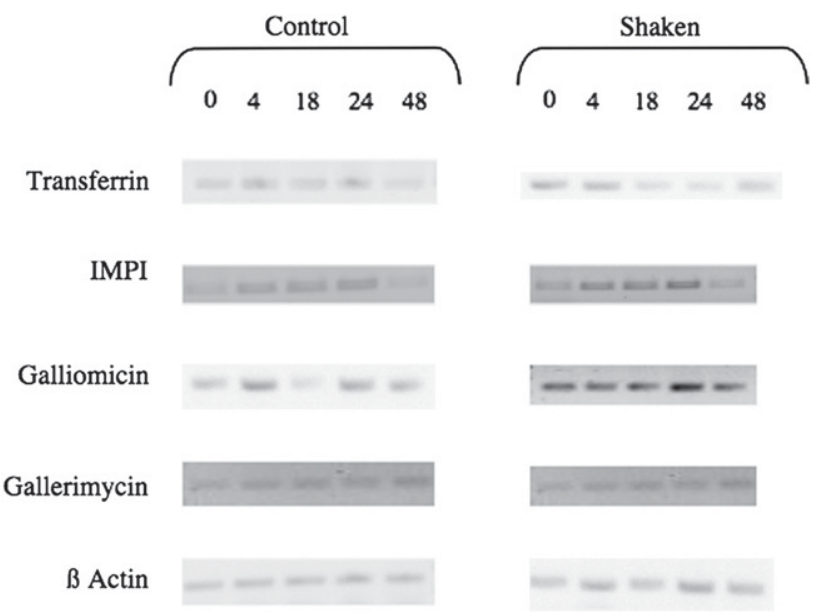

Fig. 2. RT-PCR analysis of $G$. mellonella cDNA from control and stressed larvae on a $1 \%$ agarose gel. Three independent RNA extractions were performed and PCR was carried out using primers for galiomicin, IMPI, transferrin, gallerimycin, and $\beta$ actin (housekeeping gene) on cDNA.

larvae than in controls at $p=0.004$. The expression of IMPI (Fig. 3) in physically stressed larvae is greater at all time points compared to that in the control larvae. Peak mRNA levels are reached at $24 \mathrm{~h}$ in both control and physically stressed larvae but the value is $58.2 \pm 7.1 \%$ in the former group of larvae and $92 \pm 7.2 \%$ in the latter group. mRNA

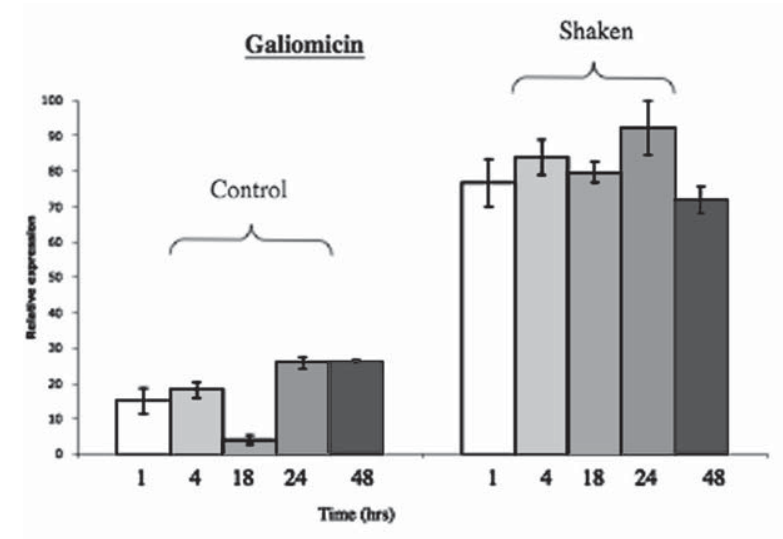

Transferrin

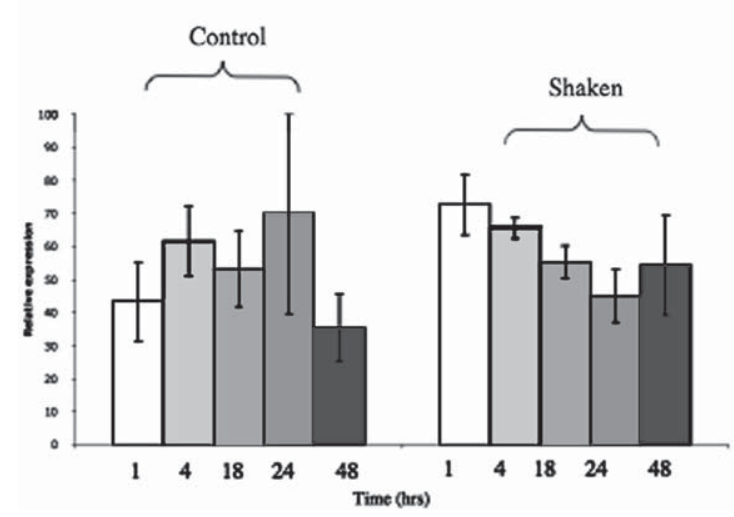

levels of IMPI at $48 \mathrm{~h}$ were statistically greater in physically stressed larvae than in controls at $p=0.002$.

The expression of transferrin (Fig. 3) in control and physically treated larvae was variable with the peak expression in control larvae being recorded at $24 \mathrm{~h}$ while the peak expression in physically challenged larvae was found at $1 \mathrm{~h}$. However, overall there was no statistically significant difference between the mRNA levels in both treated and untreated larvae and at $48 \mathrm{~h}(p=0.365)$. The mRNA levels of gallerimycin (Fig. 3) over $48 \mathrm{~h}$ were marginally higher in physically stressed larvae compared to controls but this was not deemed significantly different $(p=0.07)$.

Although the effect of physical stress on absolute levels of larval mRNA was not determined here these results indicate that the mRNA levels of galiomicin and IMPI are elevated in larvae that have been physically challenged peak at $24 \mathrm{~h}$ and this corresponds to the time at which the larvae are normally inoculated with microbial cells. mRNA levels of transferrin and gallerimycin in treated larvae are not significantly different to those in control larvae.

\subsection{Proteomic analysis of immune response of physically stressed larvae}

Two-dimensional electrophoresis has been successfully employed in Drosophila melanogaster in constructing a 2D
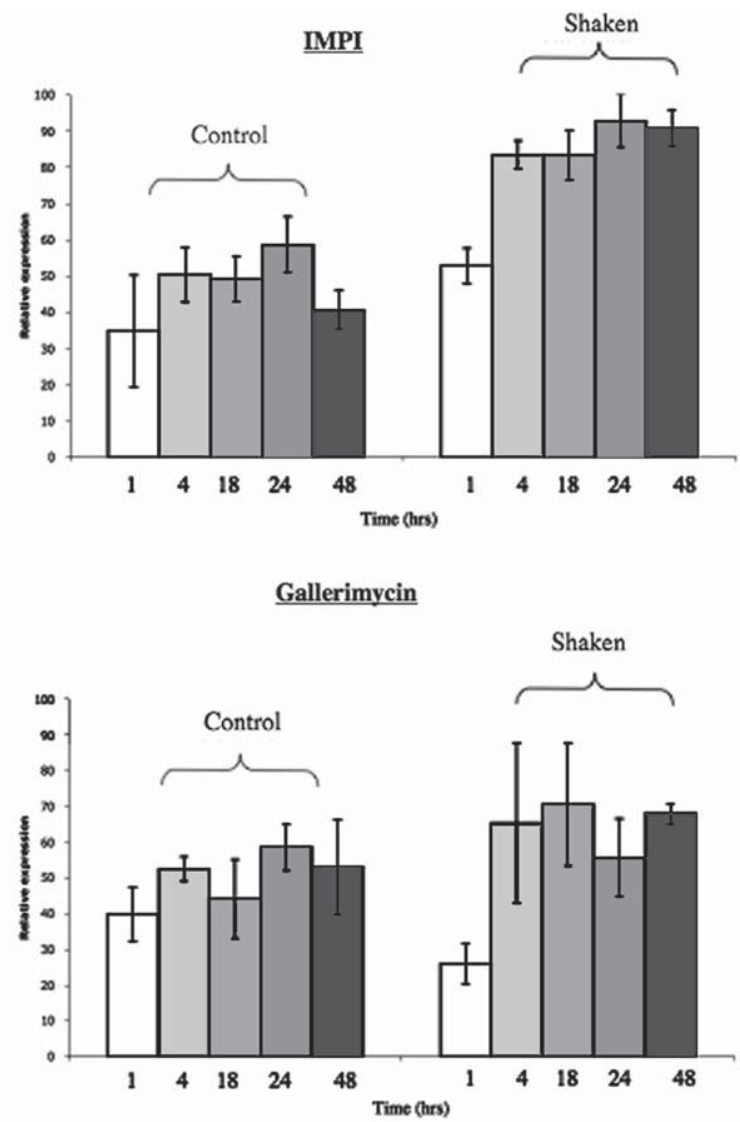

Fig. 3. Quantification of RT-PCR from control and physically challenged larvae. Densitometric quantification of PCR products from unsaturated images of RT-PCR was performed using Gene tools software (Syngene). Values were then normalised with the corresponding value of $\beta$ actin. The treatment that gave the highest level of expression was normalised to 100 and the remaining results are expressed as relative expression (\%). 


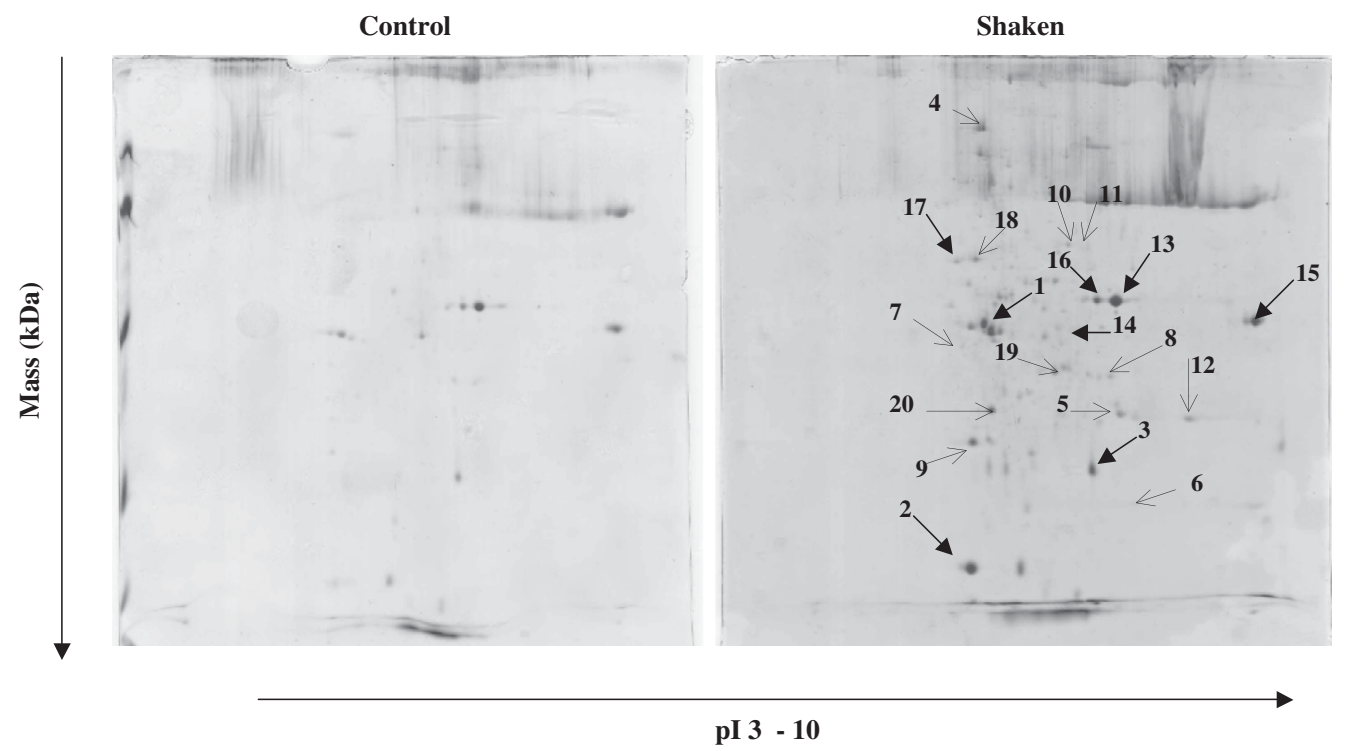

Fig. 4. Two-dimensional analysis of haemolymph samples from control and physically stressed larvae. Protein spots found in both gels with altered intensity are indicated by closed arrow. Newly induced protein spots in stressed larval haemolymph are indicated by open arrows $(\rightarrow)$.

database of haemolymph proteins [17] and this method has been utilised to analyse the immune response of Drosophila [18-20] and Bombyx mori [21]. To investigate the changes in haemolymph protein composition of larval haemolymph due to physical challenge, 2D gel electrophoresis was employed and the relevant proteins were excised and digested with trypsin for MALDI TOF analysis. Control haemolymph was obtained from larvae that had received a PBS injection. From the ImageMaster 2D analysis of the gels 19 spots were analysed for their altered spot intensities (Fig. 4). The intensity of eight peptide spots was shown to be altered in treated larvae while 11 new peptides were observed in treated larvae. Proteins were identified through ProFound peptide mapping and several proteins were identified within the haemolymph of $G$. mellonella with a wide range of functions (Table 1).

Of the spots that demonstrated alterations in intensity in treated larvae, seven showed increased intensity while one peptide (spot 14, Z score 0.43 ) showed a 2.19 fold decrease in intensity. Many of the peptides identified showed potential functions in the insect's immune response. Spot 2 ( $Z$ score 1.2) showed the greatest increase in intensity ( 7.08 fold relative to that in control larvae) and showed homology to cyclophilin 1 which displays protein folding abilities. The intensity of spot 3 ( $\mathrm{Z}$ score 0.55 ) was increased by 1.89 fold in physically challenged larvae and showed some similarities to a cysteine protease. A protein (spot 13, Z score 0.86 ) showing homology to notch inhibitor was identified in challenged larvae and its intensity was increased by 3.11 fold. In Drosophila this protein is essential in the normal development and regulation of cell growth and differentiation and may play a role in haemocyte regulation [22]. The intensity of spot 14 ( $\mathrm{Z}$ score 0.43 ) was decreased by 2.19 fold and this peptide shows similarities to myosin $1 \mathrm{~B}$ which has been associated with the control of protein traffic in multivesicular endosomes most probably through its ability to modulate with actin [23]. The intensity of spot 16 ( $\mathrm{Z}$ score 1.32$)$ was increased by 2.27 fold in treated larvae and this protein shows similarities to flotillin which controls the intracellular immunity of Dictyostelium to Mycobacterium marinum infection [24].

Table 1

Summary of proteins identified on Coomassie stained 2D gels of haemolymph from physically stressed larvae

\begin{tabular}{|c|c|c|c|c|c|c|}
\hline \multirow[t]{2}{*}{ Function } & \multirow[t]{2}{*}{ Identified proteins } & \multirow[t]{2}{*}{ Spot number } & \multirow{2}{*}{$\begin{array}{l}\text { NCBI accession } \\
\text { number }\end{array}$} & \multirow{2}{*}{$\begin{array}{l}\% \text { Protein } \\
\text { coverage }\end{array}$} & \multirow[t]{2}{*}{ Z score } & \multirow{2}{*}{$\begin{array}{l}\text { Fold expression level } \\
\text { Shake }\end{array}$} \\
\hline & & & & & & \\
\hline Immune receptor & Beta tubulin fragment & 1 & AAF98251 & 18 & 0.88 & +2.11 \\
\hline Protein folding assisting enzyme & Cyclophilin 1 CG9916-PA & 2 & NP523366 & 26 & 1.2 & +7.08 \\
\hline Electrons transfer reactions & Cysteine protease & 3 & XP767345 & 15 & 0.55 & +1.89 \\
\hline $\begin{array}{l}\text { Notch inhibitor and tumor } \\
\text { suppressor gene }\end{array}$ & $\begin{array}{l}\text { Lethal (2) giant larvae } \\
\text { gene }\end{array}$ & 13 & AA28671 & 22 & 0.86 & +3.11 \\
\hline $\begin{array}{l}\text { Believed to be responsible for } \\
\text { contraction of cell vacuole }\end{array}$ & Myosin IB & 14 & CAA15454 & 14 & 0.43 & -2.19 \\
\hline $\begin{array}{l}\text { Translocation of substrates across } \\
\text { the membrane }\end{array}$ & $\begin{array}{l}\text { EAL31705 ABC transporter } \\
\text { family }\end{array}$ & 15 & GA15454 & 10 & 0.4 & +3.56 \\
\hline $\begin{array}{l}\text { Uptake of pathogenic bacteria } \\
\text { (caveolae) scaffolding protein }\end{array}$ & Flotillin-1 & 16 & CG8200 & 23 & 1.32 & +2.27 \\
\hline Synthesis of RNA & $\begin{array}{l}\text { DNA directed-RNA polymerase } \\
\text { I largest subunit }\end{array}$ & 17 & P9185 & 9 & 0.69 & +1.5 \\
\hline
\end{tabular}


Table 2

Summary of induced proteins identified on Coomassie stained 2D gels of haemolymph from physically stressed larvae

\begin{tabular}{|c|c|c|c|c|c|}
\hline Function & Identified proteins & Spot number & NCBI accession number & $\%$ Protein coverage & Z score \\
\hline $\begin{array}{l}\text { Lysine biosynthesis; important } \\
\text { in enzyme production }\end{array}$ & Dihydrodipicolinate synthase & 4 & NP861157 & 23 & 0.91 \\
\hline Regulation of nucleotide cyclisation & GGDEF domain protein & 5 & YP271328 & 12 & 0.39 \\
\hline Clotting protein & ENSANGP0000002783 & 6 & XP_552073 & 14 & 0.56 \\
\hline $\begin{array}{l}\text { Regulation of translation of RNA } \\
\text { into proteins }\end{array}$ & TRNA methytransferase & 7 & NP501316 & 8 & 0.31 \\
\hline Receptor for microbial pathogens & T-cell receptor joining region & 8 & CAA70369 & 11 & 0.89 \\
\hline Breaks down connective tissue & Membrane bound metallopeptidase & 9 & NP_848322 & 31 & 1.12 \\
\hline Outer membrane protein & P44 paralogue & 10 & AA032044 & 24 & 1.01 \\
\hline Control of transcription & $\begin{array}{l}\text { Zinc finger CCCH-type } \\
\text { transcription factor }\end{array}$ & 11 & NP_001010888 & 34 & 1.56 \\
\hline Unknown function & Hypothetical protein & 12 & XP675265 & 18 & 0.65 \\
\hline Signal transduction (GTPase family) & GA19685-PA & 18 & EAL27299 & 24 & 0.85 \\
\hline $\begin{array}{l}\text { Important in the elongation step of protein } \\
\text { synthesis. } 60 \text { s ribosomal protein. }\end{array}$ & CG17521 & 19 & AAG22453 & 9 & 0.53 \\
\hline
\end{tabular}

Eleven novel peptides were observed on gels prepared from haemolymph from physically stressed larvae that were not visible on gels from control larvae (Table 2). Many of these proteins have similarities with the proteins associated with cellular homeostasis (spot 4, 5, 7, 19) and immune response (spot $6,8,9,18$ ). Spot 8 (Z score 0.89 ) was identified as a peptide showing homology with $\mathrm{T}$-cell receptor joining regions and spot 9 ( $\mathrm{Z}$ score 1.12) was identified as showing similarities to a membrane bound metallopeptidase. Metallopeptidase expression has been found to be increased in mammals in response to injury [25]. Spot 6 (Z score 0.56) demonstrated similarities with ENSANGP00000019647 which contains fibrinogen-related domains involved in blood clotting which increases in Biomphalaria glabrata upon infection and is thought to be a lectin involved in the innate immune response [26].

\section{Discussion}

The insect immune system consists of cellular and humoral components and, despite the absence of a system analogous to the adaptive immune system of mammals, utilises a wide range of mechanisms to deal rapidly and effectively with pathogens and parasites [1]. Previous work has established that priming the insect immune response by exposure to a sublethal dose of a pathogen or microbial material (e.g. LPS, glucan) protects against subsequent infection from a potentially lethal dose of pathogen $[12,27]$. While immunological priming has clear advantages in terms of combating a subsequent larger infection it can have an adverse affect on survival especially when resources are limited [13]. While insects lack an adaptive immune response the ability of insects to react to a low level microbial insult gives them the opportunity to increase antimicrobial defences in order to ensure survival following a larger infection within a short period of time (e.g. 24-48 h).

In the work presented here we sought to establish whether mild physical stress altered the insect immune response to infection and if it offered any protective benefit to the insect. Larvae were gently shaken for $2 \mathrm{~min}$ in cupped hands and then incubated for $24 \mathrm{~h}$ prior to inoculation. This treatment had no adverse effect on insect survival. Our results indicate that this treatment increases the ability of larvae to survive subsequent infection with $C$. albicans. Analysis of the haemocyte density showed higher numbers in treated larvae and this has previously been correlated with a greater ability to combat infection [28]. It is possible that the elevated levels of haemocytes were due to the release of haemocytes attached to internal organs within the insect rather than the de novo synthesis new cells.

The elevated mRNA levels of genes coding for four antimicrobial peptides have been recorded previously in larvae challenged with yeast cells [12]. Elevated levels of galiomicin (a defensin) and IMPI mRNA were recorded here; however the levels of transferrin and gallerimycin mRNA were not significantly altered when compared to those in the control larvae. Differential expression of antimicrobial peptide transcripts has been recorded previously when Drosophila was subjected to infection with various microbes [10]. In terms of the cellular immune response, recent work has highlighted the appearance of a super-spreading haemocyte after microbial challenge of Manduca sexta but not following wounding [29]. These findings indicate that insects can modulate their immune responses depending upon the nature of the microbial challenge or physical stress (shaking, wounding). When exposed to a microbial pathogen the expression of a wide range of AMPs may be required whereas the response to a physical challenge (e.g. shaking, wounding) may only require the induction of a subset of antimicrobial peptides. Presumably a microbial infection is a greater threat in that the microbe may grow within the insect while a mild physical stress (e.g. damage to the cuticle, shaking) may be self-limiting, unless there is the entry of a pathogen, and may not pose an immediate threat to the insect's survival.

Analysis of the peptides in the haemolymph of physically challenged larvae revealed that the intensity of seven peptide spots was elevated, one was decreased and that 11 novel peptides were recorded in the haemolymph from treated larvae. Many of the peptides (spot 1, 2, 3 and 16) which demonstrated an increase in intensity showed similarities to proteins which play a role in the insect immune response or pathogen recognition. A number of induced peptides found in the haemolymph of physically challenged larvae showed similarities to proteins with immune response functions (spot 6, 8 and 9) 
while others were similar to the proteins involved in signal transduction (spot 18) and protein synthesis (spot 19).

The results presented here indicate that physically challenging larvae of $G$. mellonella by shaking primes the immune response and results in a reduced susceptibility to infection by yeast ( $C$. albicans) cells. Shaking of larvae resulted in an increase in the number of circulating haemocytes which may aid the insect in combating subsequent infection. The levels of mRNA of genes coding for two antimicrobial peptides ( galiomicin and IMPI) were increased but those of two other genes (transferrin and gallerimycin) were not significantly altered possibly indicating that physical stress activates a different response pathway compared to microbial infection [10]. Analysis of protein expression revealed the increased intensity of a number of peptides showing similarity with known proteins involved in cellular homeostasis or immune response. A number of induced peptides (spot 6,8 and 9) demonstrated varying levels of homology with proteins with immune functions.

While physical stress primes the immune response of $G$. mellonella to infection, the nature of this response appears to be distinct to that induced by exposure to sub-lethal doses of microbial pathogens. Further work to elucidate the pathways controlling the differential response of insects to microbial and physical challenge is warranted as it may give insights into the complexity of the regulation governing the insect immune response. It is evident that this differential response is mediated through variations in the cellular [29] and humoral [10] components of the insect immune response.

\section{Acknowledgements}

This work was supported by funding from the Higher Education Authority of Ireland through the Programme for Research in Third Level Institutes III (2002-2007).

\section{References}

[1] B. Lemaitre, J. Hoffmann, The host defense of Drosophila melanogaster, Annu. Rev. Immunol. 25 (2007) 697-743.

[2] B.E. Mansfield, M.S. Dionne, D.S. Schneider, N.E. Freitag, Exploration of host-pathogen interactions using Listeria monocytogenes and Drosophila melanogaster, Cell. Microbiol. 5 (12) (2003) 901-911.

[3] G. Cotter, S. Doyle, K. Kavanagh, Development of an insect model for the in vivo pathogenicity testing of yeasts, FEMS Immunol. Med. Microbiol. 27 (2000) 163-169.

[4] M. Brennan, D.Y. Thomas, M. Whiteway, K. Kavanagh, Correlation between virulence of Candida albicans mutants in mice and Galleria mellonella larvae, FEMS Immunol. Med. Microbiol. 34 (2) (2002) 153-157.

[5] G. Jander, L. Rahme, F. Ausbel, Positive correlation between virulence of Pseudomonas aeruginosa mutants in mice and insects, J. Bacteriol. 182 (2000) 3843-3845.

[6] G. Chamilos, M.S. Lionakis, R.E. Lewis, D.P. Kontoyiannis, Role of mini-host models in the study of medically important fungi, Lancet Infect. Dis. 7 (2007) 42-55.

[7] P. Bulet, C. Hetru, J.L. Dimarcq, D. Hoffmann, Antimicrobial peptides in insects; structure and function, Dev. Comp. Immunol. 23 (4-5) (1999) 329-344.

[8] V. Leclerc, J.M. Reichhart, The immune response of Drosophila melanogaster, Immunol. Rev. 198 (2004) 59-71.

[9] N.A. Ratcliffe, Invertebrate immunity-a primer for the non-specialist, Immunol. Lett. 10 (5) (1985) 253-270.
[10] B. Lemaitre, J.M. Reichhart, J.A. Hoffmann, Drosophila host defense: differential induction of antimicrobial peptide genes after infection by various classes of microorganisms, Proc. Natl. Acad. Sci. U. S. A. 94 (26) (1997) 14614-14619.

[11] Y. Moret, M.T. Siva-Jothy, Adaptive innate immunity? Responsive-mode prophylaxis in the mealworm beetle, Tenebrio molitor, Proc. R. Soc. Lond. B. 270 (2003) 2475-2480.

[12] D. Bergin, L. Murphy, J. Keenan, M. Clynes, K. Kavanagh, Pre-exposure to yeast protects larvae of Galleria mellonella from a subsequent lethal infection by Candida albicans and is mediated by the increased expression of antimicrobial peptides, Microbes Infect. 8 (2006) 2105-2112.

[13] Y. Moret, P. Schmid Hempel, Survival for immunity: the price of immune system activation for bumblebee workers, Science 290 (2000) 1166-1168.

[14] M. Niere, M. Dettloff, T. Maier, M. Ziegler, A. Wiesner, Insect immune activation by apolipophorin III is correlated with the lipid-binding properties of this protein, Biochemistry 40 (30) (2001) 11502-11508.

[15] B. Schumann, V. Seitz, A. Vilcinskas, L. Podsiadlowski, Cloning and expression of gallerimycin, an antifungal peptide expressed in immune response of greater wax moth larvae, Galleria mellonella, Arch. Insect Biochem. Physiol. 53 (3) (2003) 125-133.

[16] A. Clermont, M. Wedde, V. Seitz, L. Podsiadlowski, D. Lenze, M. Hummel, et al., Cloning and expression of an inhibitor of microbial metalloproteinases from insects contributing to innate immunity, Biochem. J. 382 (1) (2004) 315-322.

[17] E. Vierstraete, A. Cerstiaens, G. Baggerman, G. Van den Bergh, A. De Loof, L. Schoofs, Proteomics in Drosophila melanogaster: first 2D database of larval hemolymph proteins, Biochem. Biophys. Res. Commun. 304 (4) (2003) 831-838.

[18] E. Vierstraete, P. Verleyen, G. Baggerman, W. D’Hertog, G. Van den Bergh, L. Arckens, et al., A proteomic approach for the analysis of instantly released wound and immune proteins in Drosophila melanogaster hemolymph, Proc. Natl. Acad. Sci. U. S. A. 101 (2) (2004) 470-475.

[19] M. de Guedes, R. Vitorino, K. Tomer, M.R. Domingues, A.J. Correia, F. Amado, et al., Drosophila melanogaster larval hemolymph protein mapping, Biochem. Biophys. Res. Commun. 312 (3) (2003) 545-554.

[20] F. Levy, D. Rabel, M. Charlet, P. Bulet, J.A. Hoffmann, L. Ehret-Sabatier, Peptidomic and proteomic analyses of the systemic immune response of Drosophila, Biochimie 86 (9-10) (2004) 607-616.

[21] Y. Wang, P. Zhang, H. Fujii, Y. Banno, K. Yamamoto, Y. Aso, Proteomic studies of lipopolysaccharide-induced polypeptides in the silkworm, Bombyx mori, Biosci. Biotechnol. Biochem. 68 (8) (2004) 1821-1823.

[22] D. Strand, I. Raska, B. Mechler, The Drosophila lethal(2)giant larvae tumor suppressor protein is a component of the cytoskeleton, J. Cell Biol. 127 (1994) 1345-1360.

[23] L. Salas-Cortes, F. Ye, D. Tenza, C. Wilhelm, A. Theos, D. Louvard, et al., Myosin 1b modulates the morphology and the protein transport within multi-vesicular sorting endosomes, J. Cell Sci. 118 (2005) 4823-4832.

[24] M. Hagedorn, T. Soldati, Flotillin and RacH modulate the intracellular immunity of Dictyostelium to Mycobacterium marinum infection, Cell. Microbiol. 9 (11) (2007) 2176-2733.

[25] R. Kato, S. Kiryu-Seo, H. Kiyama, Damage-induced neuronal endopeptidase expression is regulated by leukemia inhibitory factor and deprivation of nerve growth factor in rat sensory ganglia after nerve injury, Society of Neuroscience 0270-6474/02/229410-09.

[26] C.M. Adema, L.A. Hertel, R.D. Miller, E.S. Loker, A family of fibrinogen-related proteins that precipitates parasite-derived molecules is produced by an invertebrate after infection, Proc. Natl. Acad. Sci. U. S. A. 94 (16) (1997) 8691-8696.

[27] T.J. Little, A.R. Kraaijeveld, Ecological and evolutionary implications of immunological priming in invertebrates, Trends Ecol. Evol. 19 (2004) $58-60$.

[28] D. Bergin, M. Brennan, K. Kavanagh, Fluctuations in haemocyte density and microbial load may be used as indicators of fungal pathogenicity in larvae of Galleria mellonella, Microbes Infect. 5 (15) (2003) 1389-1395.

[29] P. Dean, E.H. Richards, J.P. Edwards, S.E. Reynolds, K. Charnley, Microbial infection causes the appearance of hemocytes with extreme spreading ability in monolayers of the tobacco hornworm Manduca sexta, Dev. Comp. Immunol. 28 (2004) 689-700. 